\title{
Uma Análise Comparativa da Competitividade Econômico-financeira das Cooperativas Agroindustriais do Oeste do Paraná ${ }^{1}$
}

\author{
Paulo César da Silva Ilha², Carlos Alberto Piacenti ${ }^{3}$ e \\ Edison Luiz Leismann ${ }^{4}$
}

\begin{abstract}
Resumo: O objetivo do estudo foi o de analisar comparativamente a competitividade econômico-financeira das cooperativas agroindustriais, do oeste do Paraná, utilizando-se do procedimento metodológico de análise de cluster ou agrupamento. A análise serviu para classificar hierarquicamente em categorias de agrupamentos e medir o grau de competitividade das cooperativas. Os dados foram apropriados numa série temporal de 2011 a 2014. Com os resultados alcançados pelas cooperativas, nos aspectos de classificação hierárquica, através do gráfico dendograma (árvore), demonstrou-se que as ações de gestão, no que se referem à sustentabilidade econômico-financeira, são díspares. Nos aspectos de medidas de competitividade, classificou-se a cooperativa Copacol como a mais competitiva, comparada aos padrões estabelecidos.
\end{abstract}

Palavras-chaves: cooperativa agroindustrial, competitividade, análise econômico-financeira.

\begin{abstract}
The aim of the study was to analyze comparatively the economic and financial competitiveness of agro-industrial cooperatives, the western Paraná, using the methodological procedure of cluster analysis or grouping. The analysis served to classify hierarchically in groups of categories and measure the degree of competitiveness of cooperatives. Data were appropriate in a time series from 2011 to 2014. The results achieved by the cooperatives, in the aspects of hierarchical classification, through the dendrogram graph (tree), it was shown that management actions, in referring to the economic financial sustainability, is mixed. The aspects of competitiveness measures, Copacol was ranked as the most competitive cooperative, compared to set standards.
\end{abstract}

Key-words: agribusiness cooperative, competitiveness, economic and financial analysis.

Classificação JEL: P13.

DOI: http://dx.doi.org/10.1590/1234-56781806-94790560106

1. Data de submissão: 11 de dezembro de 2015. Data de aceite: 20 de agosto de 2017.

2. Universidade Estadual do Oeste do Paraná. Toledo, Paraná, Brasil. E-mail: paulocesarilha@yahoo.com.br

3. Universidade Estadual do Oeste do Paraná. Toledo, Paraná, Brasil. E-mail: piacenti8@gmail.com

4. Universidade Estadual do Oeste do Paraná. Toledo, Paraná, Brasil. E-mail: elleismann@gmail.com 


\section{Introdução}

A região oeste do Paraná tem se destacado no cenário nacional e internacional como importante centro de produção agroindustrial, sobretudo no que se refere às atividades de avicultura, suinocultura, laticínios, produção de soja, milho e outros. Com essa performance cria-se um ambiente sui generis para estudos científicos que possam auxiliar o desenvolvimento regional.

Constituída em bases comunitárias e composta principalmente por descendentes de imigrantes de origem europeia, vindos dos estados do Rio Grande do Sul e de Santa Catarina, a região oeste atribuiu, desde muito cedo, o modelo organizacional de produção agropecuária às cooperativas. Essas têm contribuído de forma importante para a consolidação de uma região desenvolvida, que contemporaneamente se lançam em atuações de mercado externo, colocando em desvelo suas competitividades.

Os estudos sobre competitividades das cooperativas se apresentam com destaque nas agendas de assuntos do setor produtivo local, como fator relevante nas decisões que nortearão o futuro desses empreendimentos. Segundo Presno (2001), as cooperativas agroindustriais influenciam na competitividade e na funcionalidade no sistema agroalimentar regional, pois essas organizações demonstraram no passado que são capazes de manter lugares de destaque nos mercados, liderando, muitas vezes, o desenvolvimento regional. No entanto, com o processo de globalização da economia, esse cenário passa a ser ameaçado pelo acirramento concorrencial e o aparecimento de novas tecnologias, e a tendência é que cada vez mais as empresas deixem de ser apenas locais e passem a competir no mercado internacional. A concorrência no mercado interno ou externo exige que as empresas sejam mais competitivas (PORTER, 1989).

Nesse sentido, a discussão sobre a temática de competitividade das cooperativas agroindustriais do oeste do Paraná - Copagril, Lar, C. Vale, Copacol e Coopavel - dar-se-á neste estudo, a partir do comportamento da firma cooperativa, frente a duas empresas: uma, a cooperativa Coamo, considerada a maior da América Latina ${ }^{5}$, e a outra, a BRF, de capital ${ }^{6}$ para a compreensão do cooperativismo como empreendimento, sem, contudo, negligenciar a cooperativa sob a ótica do cooperado, da sua função utilidade e da maximização de suas satisfações, pois se sabe que a firma cooperativa se apresenta como uma economia intermediária entre as economias associadas dos cooperados e o mercado.

A disposição para a prática da cooperação em cooperativas advém, em grande parte, da pressão competitiva em conjunturas de economias de mercado - esta foi a grande razão para o surgimento da cooperativa de Rochdale ${ }^{7}$. A dualidade existencial de cooperar

5. A "maior cooperativa da América Latina" (Coamo), localizada no município de Campo Mourão, estado do Paraná, de acordo com o site RankBrasil (2013).

6. O entendimento dado neste estudo para a empresa de capital" (BRF-Brasil Foods) é caracterizado pela organização com fins lucrativos.

7. Rochdale: bairro em Manchester (Inglaterra), onde 27 tecelões e uma tecelã fundaram a "Sociedade dos Probos Pioneiros de Rochdale" em 21 de dezembro de 1844. A primeira cooperativa a funcionar no mundo que serve como marco histórico para o cooperativismo atual (OCB, 2015). 
ex-ante $e^{8}$ para competir ex-post ${ }^{9}$ faz parte do pragmatismo das ações das cooperativas. Não se trata de estar ferindo os ideários cooperativistas, mas, sim, de abordar a cooperação de uma forma mais ampla, do ponto de vista da sua competitividade.

Segundo Souza, Braga e Ferreira (2011), os estudos sobre eficiência têm sido feitos com o objetivo de definir padrões relacionados com gestão e busca de melhores níveis de competitividade. A cooperativa tem que objetivar uma forma mais eficiente, sob o ponto de vista econômico e com maior eficácia, sob a ótica social, de modo a garantir, em médio e longo prazo, que essas organizações tenham um continuado processo de crescimento, acompanhado do necessário sucesso nos mercados. A própria legislação cooperativista trata as cooperativas como sociedades de pessoas, sem fins lucrativos, de natureza civil, não sujeitas à falência (Lei n. 5.764/71). Atribuir tão somente a uma cooperativa natureza econômica ou social não atenderia às necessidades de seus participantes associados e nem mesmo poderia apresentar-se como as firmas que conseguem alocar melhor os recursos produtivos da sociedade local, pois uma cooperativa voltada para a eficiência empresarial sem a mais leve intenção de lucrar à custa dos cooperados, nem ferir ou modificar seus princípios básicos, é que dará a verdadeira dimensão do cooperativismo moderno e condições favoráveis a seu desenvolvimento (ILHA, 2010).

Esta particularidade das cooperativas que não buscam o lucro nas operações com os seus cooperados (neste caso, produtores rurais) coloca-as em desvantagem em relação à empresa não cooperativa, pois esta tende a maximizar o seu lucro, igualando o seu custo marginal à sua receita marginal em todas as operações (BIALOSKORSKI NETO, 2012). Para o mesmo autor, esse detalhe é importante quanto à política de investimentos e, portanto, de capacidade competitiva das firmas cooperativas que inicialmente poderiam ser prejudicadas.

Nesse sentido, entender a natureza das capacidades competitivas é essencial para a previsão de capitais,

8. O termo ex-ante é uma expressão neolatina que significa "antes do evento". Neste caso, as ações de cooperação que os cooperados realizam com a cooperativa antecipadamente de elas competirem no mercado.

9. O termo ex-post significa "após o evento". Neste caso, a cooperação recebida anteriormente constitui condição indispensável para a cooperativa competir posteriormente nos mercados. para determinação do processo de produção, para o marketing, para a avaliação de estratégias de inter-relações e para novos empreendimentos, de modo que uma empresa possa realmente criar e sustentar uma vantagem competitiva (PORTER, 1991; CHURCHILL e PETER, 2003; GREENWALD e KAHN, 2006).

A concorrência está no âmago do sucesso ou do fracasso das empresas e leva à adoção de configurações eficientes de mercado, determinando a adequação das atividades que podem contribuir para seu desempenho, como inovações, uma cultura coesa ou uma boa implementação. A estratégia competitiva tem sucesso quando leva a empresa a alcançar seus objetivos, uma vez que a busca de uma posição competitiva favorável é fundamental no setor em que ela atua. A estratégia competitiva visa estabelecer uma posição lucrativa e sustentável contra as forças que determinam a concorrência, para Porter (1991); Churchill e Peter (2003) e para Farina et al. (1997).

Abordando sobre vantagens competitivas, Greenwald e Kahn (2006), afirmam que só existem três tipos reais: os de suprimento, os de demanda e de economias de escala. As vantagens de suprimentos dizem respeito aos custos que permitem à empresa produzir e entregar seus produtos e serviços a custos menores que os de seus concorrentes. Já nas vantagens de demanda, as empresas têm acesso à demanda de mercado que seus concorrentes não conseguem atender e, nas economias de escalas, permitem que os custos por unidade diminuam à medida que o volume aumente até encontrar o ponto mínimo.

Também há que ser considerado que, em alguns casos, as vantagens competitivas não advêm somente pela eficiência administrativa, mas por interesses de proteção governamental ou até mesmo por acesso a informações privilegiadas (ILHA et al., 2016).

Sendo assim, vários defensores do cooperativismo reivindicam uma posição privilegiada do governo por entenderem que o empreendimento cooperativista é uma forma organizacional que propicia uma série de vantagens para os cooperados e para a sociedade em geral. Isto decorre da forma organizacional que permite maior distribuição de renda e resultados e do fato de a cooperativa ser um agente que consegue estabelecer níveis mais favoráveis de preços (BIALOSKORSKI NETO, 1999).

A despeito dessa argumentação, se o cooperado tivesse plena consciência cooperativista, transformaria 
a posição desfavorável da cooperativa, sem maximizar seu lucro nas operações com os cooperados, em aumentos de escala na entrega total da produção e nas aquisições de insumos para as suas atividades rurais, convertendo uma limitação numa vantagem competitiva.

\section{Fundamentação teórica}

O entendimento de competitividade não se apresenta da mesma forma e nem se mantém no tempo. Existem diversas bases teóricas, muitas vezes comandadas por ideologias distintas, que criam análises, envolvendo enfoques organizacionais, institucionais, sociais, econômicos e outros, que geram uma complexidade para compreensão da dinâmica das organizações e dos fatores, envolvidos no processo de decisão. Neste caso, é importante destacar, numa rápida análise, visões diferenciadas sobre competitividade para, em seguida, justificar a posição aqui assumida.

Neste entendimento, a competitividade de uma empresa não pode ser compreendida, observando-se a empresa como um todo. Ela tem sua origem nas inúmeras atividades distintas, mas complementares, que realiza em sua gestão (PORTER, 1989). Por sua vez, para o mesmo autor, o fracasso das estratégias competitivas deve-se à incapacidade de traduzir uma estratégia geral em etapas de ações específicas necessárias para se obter vantagem competitiva.

Para Farina et al. (1997), a competitividade tem um significado claro aplicada às empresas. Do ponto de vista das teorias de concorrência, os autores definem competitividade como a capacidade sustentável de uma empresa em sobreviver e, preferencialmente, crescer em mercados novos e em que já atua.

$\mathrm{Na}$ complementaridade dessa linha de pensamento, os mesmos autores apresentam o enfoque sistêmico da teoria das organizações industriais de Williamson, com destaque para o enfoque dos custos de transações, inserindo na discussão de competitividade o ambiente institucional e as variáveis transacionais - especificidades de ativos, incerteza e frequência -, estabelecendo as relações entre estruturas de governança responsáveis pela coordenação das transações, pelo comportamento e pelo desempenho das organizações. Nesse sentido, as empresas devem buscar ambientes mais favoráveis para minimizar custos de transações no mercado, organizando melhor a produção com adoção de estrutura de governança mais eficiente. As diferentes formas de organizar a produção determinam a capacidade de reação das empresas às mudanças do ambiente competitivo (FARINA et al., 1997).

A teoria das organizações tem suprido a teoria evolucionista de importantes conceitos de competitividade. É explorando essas contribuições que Dosi e Friman (1992), propõem o conceito de coerência corporativa, que deve ser explicado como complexa relação entre o processo de aprendizado, padrão de dependência, oportunidades tecnológicas e complementaridade dos ativos.

No entanto, uma das mais contundentes abordagens de competitividade empresarial vem de Schumpeter, considerado um dos mais expressivos economistas da primeira metade do século XX. Para ele, o principal funcionamento da economia capitalista está baseado num ininterrupto processo de introdução e difusão de inovações, tendo como unidade de análise da concorrência schumpeteriana a empresa, pois é neste ambiente que se decide e apropriam-se os ganhos, tendo o mercado como espaço principal da interação competitiva (SCHUMPETER, 1982).

Outra forma clássica de definir competitividade está nas relações institucionais, no enfoque sistêmico, entendendo que a competitividade ultrapassa as fronteiras da firma e vai depender de uma integração sistêmica entre os diversos agentes, situadas a montante e a jusante da unidade de produção. A compreensão desse processo e dos fatores que influenciam a definição das estratégias das firmas ou instituições passa a ser o grande desafio da teoria econômica e das organizações (ZYLBERSZTAJN, 1995).

Estes fatos, rapidamente apresentados, servem para justificar a importância do estudo e ressaltar a complexidade do tratamento sobre competitividade empresarial. Porém, o lócus, à guisa dessa discussão será a empresa cooperativa. Tão ou mais importante que o conhecimento das abordagens é medir o grau de competitividade em relação aos seus concorrentes, principalmente aqueles que se destacam no cenário como líderes de mercado.

Medir comparativamente o grau de competitividade das cooperativas em análise consistirá, assim, em se determinar uma grandeza que defina a proximidade ou o afastamento que seu perfil competitivo 
tenha entre elas e em relação ao perfil competitivo de duas empresas (Coamo e BRF), que se determinará como padrões competitivos. Isso, por si só, é um desafio considerável, mas propiciará informações relevantes, senão decisivas, para a determinação de estratégias que passarão a ser ingredientes cruciais para sua capacidade de respostas a mudanças no ambiente externo.

A competitividade empresarial é um fenômeno bastante complexo, como já foi dito e, para poder medi-la, será necessário, antes, estabelecer algumas definições básicas para suportar o desenvolvimento que se propõe. Tais conceitos, no entanto, serão admitidos como pressupostos para este estudo, uma vez que a discussão de sua fundamentação transcende o objetivo da proposição que se apresenta.

Assim, adotando a fundamentação de Ilha et al. (2016), são assumidas no desenvolvimento deste estudo três definições basilares para a proposição da medida do grau de competitividade de uma cooperativa: o que se considerará como competitividades empresariais, variáveis competitivas e perfil competitivo.

No conceito de competitividade empresarial, propõe-se adotar, como um pressuposto, uma definição que integre dois aspectos sobre diferentes enfoques: o econômico e o financeiro. Dessa forma, a proposta de medir a competitividade empresarial irá considerar a seguinte problematização: em decorrência dos desafios apresentados pelo ambiente competitivo, as cooperativas agroindustriais do oeste do Paraná estão perfeitamente estruturadas, econômico-financeira, propiciando condições favoráveis de ascensão e atualização ao processo tecnológico e de produção, fazendo com que obtenham alta competitividade nos mercados, sem descaracterizar ou ferir seus ideais, agregando mais valor aos recursos produtivos da sociedade regional?

Para ser possível a medida do grau de competitividade da firma cooperativa, será necessário traduzir todas as características competitivas enunciadas na definição acima na forma de variáveis, que serão denominadas de "variáveis competitivas". Para ilustrar o desenvolvimento que se pretende, assume-se também como pressuposto neste estudo um conjunto de 15 variáveis do enfoque econômico-financeiro, do tipo quantitativas, que têm como finalidade caracterizar o desempenho competitivo de cada uma das cooperativas agroindustriais do oeste do Paraná.

Como resultado dessa estrutura conceitual, este estudo assume, como terceiro pressuposto, o estabele- cimento da definição de perfil competitivo de cooperativas que será o conjunto dos valores, assumido por todas as variáveis competitivas em quatro anos.

Considerando-se todos os aspectos apresentados, o objetivo geral deste estudo é analisar comparativamente a competitividade econômico-financeira das cooperativas agroindustriais do oeste do Paraná.

\section{Procedimentos metodológicos}

Os procedimentos adotados para a interpretação dos dados foram o de análise de cluster ou agrupamento, utilizando-se de técnicas estatísticas multivariadas para um estudo de caso, com conotação de pesquisa exploratória. De acordo com Yin (2010), o estudo de caso é "um dos empreendimentos mais desafiadores na pesquisa" (p. 23). Para tanto, as categorias de análise foram operacionalizadas, ou seja, traduzidas em conceitos mensuráveis, através de dados secundários, o que tornou possível visualizar rapidamente os diversos meios em que estão inseridos os objetos de estudo, sejam estes internos ou externos à empresa. Tais técnicas permitiram obter, com baixo custo, internamente ou fora da empresa, uma grande variedade de dados para investigação, de tal modo que se conseguiu atingir os objetivos inicialmente propostos no estudo e, ao mesmo tempo, pode-se atender os critérios de maior eficácia e mais confiabilidade de informações. Conforme Hair Jr. et al. (2009), a análise multivariada auxilia na formulação de questões relativamente complexas de forma específica e precisa, possibilitando a condução de pesquisas teoricamente significativas.

Para a viabilização dos cálculos da análise multivariada, utilizou-se o programa Statistical Product and Service Solutions $(\mathrm{SPSS})^{10}$, amplamente difundido no meio estatístico.

10. O Statistical Product and Service Solutions (SPSS) é um software aplicativo (programa de computador) do tipo científico. Originalmente, o nome era acrónimo de Statistical Package for the Social Sciences - pacote estatístico para as ciências sociais, mas na atualidade a parte SPSS do nome completo do software (IBM SPSS) não tem significado. Pacote este de apoio à tomada de decisão que inclui: aplicação analítica, Data Mining, Text Mining e estatística que transformam os dados em informações importantes (FREI, 2006). 


\subsection{A determinação das variáveis analisadas}

O entendimento do que seja competitividade para este enfoque da pesquisa está configurada na assertiva de que a competitividade das cooperativas possui uma relação com as variáveis, apresentadas no Quadro 1.

Neste estudo, assumiu-se um conjunto de 15 variáveis quantitativas adotadas por Brighmam e Houston (1999); Marion (2012) e Silva (2012), que tiveram como finalidade caracterizar o desempenho competitivo econômico-financeiro das cooperativas em estudo.

\subsubsection{As Variáveis Quantitativas (15)}

Giro do Ativo Total, Estruturas de Capitais (DC - WACC), Geração de Valor Agregado da Ação ou Quota-Parte (EVA) Relativo, Retorno sobre as vendas, Retorno sobre o Ativo (ROA), Retorno sobre o Patrimônio Líquido (ROE), Índice Liquidez Corrente, Índice Liquidez Seca, Índice Liquidez Imediata, Índice Liquidez Geral, Índice de Endividamento Geral, Composição do Endividamento de Curto Prazo, Composição do Endividamento de Longo Prazo, Sustentabilidade do Endividamento.

As variáveis não foram medidas simplesmente pelas suas grandezas, mas sim pela capacidade de sustentabilidade econômico-financeira da cooperativa. $\mathrm{O}$ termo sustentabilidade denota o entendimento de que os resultados, advindos das medições das variáveis, refletirão a capacidade de competitividade. Para tanto, duas variáveis foram desenvolvidas pelos autores exclusivamente para este estudo, não tendo referência direta na literatura pertinente sobre o assunto, como são os casos das medições das variáveis: "Geração de Valor Agregado da Ação ou Quota-Parte" (EVA) Relativo e "Sustentabilidade do Endividamento"; as demais são perfeitamente conhecidas e referenciadas na literatura.

\subsection{A mensuração das variáveis quantitativas}

As equações apresentadas no subcapítulo 3.2 são reproduções e criações a partir de informações de autores como: Brighmam e Houston (1999); Matarazzo (2010); Assaf Neto e Lima (2011); Marion (2012) e Silva (2012). A crescente complexidade do mundo dos negócios determina que os profissionais das áreas econômico-financeiras desenvolvam uma visão mais integrativa da empresa e de seu relacionamento com o ambiente externo. Nesse sentido, necessita-se da compreensão dos valores em relação a seus concorrentes e da sua capacidade de competividade no mercado que lhes propiciam a tomada de decisões mais estratégicas.

\subsubsection{O cálculo do giro do ativo total}

O Giro do Ativo Total corresponde a um índice de eficiência no uso dos Ativos. Quanto maior este índice, mais competitiva é a empresa. É dado pelas Receitas

Quadro 1. Variáveis competitivas econômico-financeiras

\begin{tabular}{|l|l|c|}
\hline \multicolumn{1}{|c|}{ Enfoque } & \multicolumn{1}{|c|}{ Variável Competitiva } & Como Medir \\
\hline \multirow{5}{*}{ Econômico } & Giro do Ativo Total & RL/ATM \\
\cline { 2 - 3 } & Estruturas de Capitais & DC \\
\cline { 2 - 3 } & Geração de Valor Econômico Agregado da Ação ou Quota-Parte - EVA Relativo & WACC \\
\hline \multirow{5}{*}{ Financeiro } & Retorno sobre as vendas & LL ou SL/V \\
\cline { 2 - 3 } & Retorno sobre o Ativo - ROA & RA/AT \\
\cline { 2 - 3 } & Retorno sobre o Patrimônio Líquido - ROE & LL ou SL/PL \\
\cline { 2 - 3 } & Índice Liquidez Corrente & AC/PC \\
\cline { 2 - 3 } & Índice Liquidez Seca & (AC - estoques)/PC \\
\cline { 2 - 3 } & Índice Liquidez Imediata & AD/PC \\
\cline { 2 - 3 } & Índice Liquidez Geral & CT/AT \\
\cline { 2 - 3 } & Índice de Endividamento Geral & PC/CT \\
\cline { 2 - 3 } & Composição do Endividamento de Curto Prazo & DFL/LO ou SO (LAJIR) \\
\cline { 2 - 3 } & Composição do Endividamento de Longo Prazo & ELP/CT \\
\cline { 2 - 3 } & Sustentabilidade do Endividamento & (PCP) \\
\hline
\end{tabular}

Fonte: Determinado pelo autor, a partir de Silva et al. (2012). 
Líquidas sobre o Ativo Total Médio, apresentado na equação 1:

$$
\text { Giro do Ativo Total }=\frac{\text { RL }}{\text { ATM }}
$$

Sendo que:

$\mathrm{RL}=$ Receitas Líquidas

ATM $=$ Ativo Total Médio

\subsubsection{Os cálculos das estruturas de capitais (DC - WACC)}

A empresa primeiro analisa uma série de fatores e, então, estabelece uma Estrutura de Capital desejada.

A dívida em relação a Capital de Terceiros (DC) irá indicar qual a "dependência" dos negócios em relação a recursos de terceiros (bancos, fornecedores, recursos trabalhistas e tributários). Uma participação próxima a 1 denota insolvência e extrema dependência de terceiros. O ideal, em termos de competitividade, é que esta participação seja igual ou inferior a 0,6 , a não ser que as dívidas (capital de terceiros) estejam, em sua maior parte, no longo prazo e com juros baixos, para poder enfrentar riscos monetários. Calcula-se através da equação 2 :

$$
\mathrm{DC}=\frac{\mathrm{PCM}+\mathrm{ELPM}}{\mathrm{ATM}}
$$

Sendo que:

$\mathrm{PC}=$ Passivo Circulante Médio

ELP $=$ Exigível a Longo Prazo Médio

ATM $=$ Ativo Total Médio

O Custo Médio Ponderado de Capital ${ }^{11}$ (WACC) é uma medida de eficiência financeira: quanto menor, melhor. Pode ser intuitivamente definido como "a média ponderada dos custos dos diversos componentes de financiamento, incluindo dívida, Patrimônio Líquido e títulos híbridos, utilizados por uma empresa para financiar suas necessidades financeiras". A ideia que está por trás da fórmula do WACC é simples e intuitiva. Se um novo projeto é lucrativo o suficiente

11. Para o cálculo do WACC, necessita-se do percentual pelo qual foi pago juros sobre o Capital Social. Como esta informação não se obtém no balanço e também é de difícil acesso nas empresas (informação restrita), optar-se-á pelo uso da taxa média anual da SELIC (Sistema Especial de Liquidação e de Custódia), que é um índice pelo qual as taxas de juros são cobradas pelos bancos no Brasil. para pagar os juros sobre a dívida contraída para financiá-lo e para gerar uma taxa de retorno superior à esperada sobre o patrimônio investido, deve-se considerá-lo como um bom projeto. Essa taxa de retorno superior ao esperado nada mais é do que uma extrapolação da taxa de retorno, exigida pelos investidores da empresa. É calculado através da equação 3:

$$
\begin{aligned}
& \mathrm{WACC}=\mathrm{Ke}[\mathrm{E} /(\mathrm{E}+\mathrm{D}+\mathrm{PS})]+ \\
& +\mathrm{Kd}[\mathrm{D} /(\mathrm{E}+\mathrm{D}+\mathrm{PS})]+\mathrm{Kps}[\mathrm{PS} /(\mathrm{E}+\mathrm{D}+\mathrm{PS})]
\end{aligned}
$$

Sendo que:

$\mathrm{Ke}=$ custo do Patrimônio Líquido.

$\mathrm{Kd}=$ custo das dívidas após tributos.

Kps $=$ custo das ações preferenciais ou quotas-partes.

$\mathrm{E} /(\mathrm{E}+\mathrm{D}+\mathrm{PS})=$ proporção, em valor de mercado, do Patrimônio Líquido em relação ao valor do mix de financiamento.

$\mathrm{D} /(\mathrm{E}+\mathrm{D}+\mathrm{PS})=$ proporção, em valor de mercado, da dívida em relação ao valor do mix de financiamento.

$\mathrm{PS} /(\mathrm{E}+\mathrm{D}+\mathrm{PS})=$ proporção, em valor de mercado, das ações preferenciais ou quotas-partes em relação ao valor do mix de financiamento.

\subsubsection{O cálculo do EVA Relativo}

O Valor Econômico Agregado (EVA) é mensurado para identificar o quanto foi efetivamente criado de valor para os quotistas ou acionistas em um determinado período de tempo. O importante é que quanto maior o valor, mais competitiva pode ser a empresa. A equação 4 indica o cálculo do Valor Econômico Agregado (EVA), dado por:

$$
\mathrm{EVA}=(\mathrm{ROIC}-\mathrm{WACC}) \mathrm{CI}
$$

Sendo que:

ROIC $=$ Retorno sobre o Capital Investido WACC $=$ Custo Médio Ponderado de Capital $\mathrm{CI}=$ Capital Investido ou Ativo Econômico

Calculando-se o EVA, criou-se o EVA Relativo ${ }^{12}$, que significa o valor do EVA por quota-parte ou ação comparativamente entre empresas. Com esse conceito,

12. Aplicar-se-á um redutor por efeitos tributários ao EVA da empresa BRF, considerando que o EVA deva ser calculado após descontos de Imposto de Renda de Pessoa Jurídica IRPJ $(25 \%)$ e da Contribuição Social sobre o Lucro Líquido - CSLL (9\%). O redutor não será aplicado às cooperativas, haja vista que elas não pagam Imposto de Renda e nem Contribuição sobre o Lucro nas operações com seus cooperados. 
elimina-se o problema de tamanho, sendo que, quanto maior o EVA Relativo, mais competitiva é a empresa. Calcula-se, conforme equação 5, elaborado pelos autores do estudo:

$$
\mathrm{EVA}_{\text {relativo }}=\frac{\text { EVA }}{\text { Patrimônio Liquido }}
$$

\subsubsection{O cálculo das taxas de retornos (lucratividade ou sobras)}

Quanto maiores as Taxas de Retornos, melhores elas serão. Calcula-se, conforme equações 6, 7 e 8:

$$
\mathrm{RV}=\frac{\text { Lucro ou Sobra Liquida }}{\text { Vendas }} \cdot 100
$$

$$
\text { ROA }=\frac{\text { Resultado Ajustado }}{\text { Ativo Total }} \cdot 100
$$

$$
\text { ROE }=\frac{\text { Lucro Liquido ou Sobra Liquida }}{\text { Patromônio Liquido }} \cdot 100
$$

Sendo que:

$\mathrm{RV}=$ Retorno sobre as Vendas.

$\mathrm{ROA}=$ Retorno do Ativo

$\mathrm{ROE}=$ Retorno do Patrimônio Líquido.

\subsubsection{O cálculo da liquidez}

Quanto maiores em relação à média do setor, melhor para Liquidez (menor risco de não pagar as contas em dia). Porém, será pior para a rentabilidade, pois esses ativos maiores representam aplicações de recursos em contas com baixos ou nenhum retorno (caixa, por exemplo) e que têm origens de alto custo. Calcula-se, conforme equações 9, 10, 11 e 12:

Luquidez Corrente $=\frac{\mathrm{AC}}{\mathrm{PC}}$

Liquidez Seca $=\frac{A C-\text { Estoque }}{\text { PC }}$

Liquidez Imediata $=\frac{\mathrm{AD}}{\mathrm{PC}}$

13. O Resultado Ajustado corresponde ao resultado gerado pela empresa, deduzidos de tributos e excluídos de despesas financeiras.
Liquidez Geral $=\frac{A C+\text { Realizável a Longo Prazo }}{\mathrm{PC}+\text { Exigivel a Longo Prazo }}$

Sendo que:

$\mathrm{AC}=$ Ativo Circulante.

$\mathrm{PC}=$ Passivo Circulante.

$\mathrm{AD}=$ Ativo Disponível.

\subsubsection{O cálculo do endividamento}

Quanto maior for a participação de dívidas na estrutura de Capital, maior é o risco da empresa; e quanto menor custo dos fundos de terceiros em relação aos fundos próprios, menor o custo total de Capital. Portanto, empresas com menor endividamento são mais competitivas. Calcula-se com as equações 13, 14 e 15:

Endividamento Geral $=\frac{\mathrm{CT}}{\mathrm{AT}} \cdot 100$

Endividamento de Curto Prazo $=\frac{\mathrm{PC}}{\mathrm{CT}} \cdot 100$

Endividamento de Longo Prazo $=\frac{\text { ELP }}{\mathrm{CT}} \cdot 100$

Sendo que:

AC $=$ Ativo Circulante.

$\mathrm{PC}=$ Passivo Circulante.

$\mathrm{AD}=$ Ativo Disponível.

\subsubsection{O cálculo da sustentabilidade do endividamento}

Para o cálculo da Sustentabilidade do Endividamento, sugere-se um índice aceitável de até $50 \%$ para melhor competitividade. O cálculo é apresentado pelos autores do estudo, na equação 16:

Sustentabilidade do Endividamento $=\frac{\text { DFL }}{\text { LAJIR }} \cdot 100$ Sendo que:

DFL $=$ Despesas Financeiras Líquidas.

LAJIR $=$ Lucro ou Sobra Operacional.

\subsection{A determinação dos agrupamentos}

Existe uma série de ideias para formação de agrupamentos, mas algumas nem sempre são aceitas universalmente, embora todas se baseassem, fundamentalmente, em dois conceitos básicos, sugeridos por Bussab, Miazaki e Andrade (1990) e Frei (2006), que são: coesão interna dos objetos e isolamento externo entre os grupos. 
No caso de agrupamento, usou-se a ideia de parecença entre enfoques, cujo conceito tem como ideia-chave a parecença entre cooperativas.

As técnicas de agrupar podem ser classificadas em categorias, em que as técnicas hierárquicas são as mais utilizadas na literatura. Nessas técnicas hierárquicas, as cooperativas são classificadas em grupos, em diferentes etapas, de modo hierárquico, produzindo uma árvore de classificação (dendograma).

Para essa análise, utilizou-se o método de ligação completa ou do vizinho mais longe (complete linkage), apresentado por Bussab, Miazaki e Andrade (1990), para as equações 17 e 18:

$$
D_{(k i j)}=\frac{\left(d_{k i}+d_{i j}\right)}{2}
$$

Sendo que:

$D_{(k i) j}$ - É a distância entre o agrupamento $(k i)$ e o agrupamento $(j)$;

$d_{k i}$ e $d_{i j}$ - São as distâncias entre a maior distância dos membros dos agrupamentos $(k)$ e $(j)$ e dos agrupamentos (i) e (j).

O nível de similaridade $S_{(i j)}$ entre dois grupos (i) e (j) é dado por:

$$
S_{(i j)}=100\left(1-\frac{d_{(i j)}}{d_{(\max )}}\right)
$$

Sendo que:

$d_{(\max )}=$ Valor máximo da matriz distância

\subsection{A determinação da distância competitiva e dissimilaridade}

Com base nas técnicas utilizadas, estabeleceu-se um coeficiente de parecença que mostrou as dissimilaridades entre os perfis competitivos das empresas, consideradas como referenciais competitivos e a cooperativa, aquela cuja competitividade se desejou medir e que foi analisada comparativamente aos padrões estabelecidos.

Nesse estudo, com as variáveis quantitativas, foi utilizada como coeficiente de parecença a distância euclidiana simples entre as empresas padrões (empresas A e B tomadas como referências) e a cooperativa (empresa C em estudo), determinada pela equação 19, conforme Bussab, Miazaki e Andrade (1990):

$$
D_{e}(\mathrm{~A}, \mathrm{~B}, \mathrm{C})=\left\{\sum\left[x_{i}(\mathrm{~A}, \mathrm{~B})-x_{i}(\mathrm{C})\right]^{2}\right\}^{1 / 2}
$$

Sendo que:

$D_{e}(\mathrm{~A}-\mathrm{C}$ e B - C) - É a distância euclidiana entre as empresas (A, B) (referências) e a cooperativa empresa (C) (caso em estudo);

$x_{i}(\mathrm{~A}, \mathrm{~B})-\mathrm{E}$ a variável (i) das empresas (A, B) (referências);

$x_{i}(\mathrm{C})$-É a variável (i) da cooperativa empresa (C) (caso em estudo).

Como se observa, a distância euclidiana procura determinar o quanto o perfil competitivo das empresas A e B diferem do perfil competitivo da cooperativa empresa $\mathrm{C}$, levando-se em conta apenas as variáveis quantitativas. Assim, para os mesmos autores, aplicando-se esse conceito às variáveis competitivas consideradas por este estudo, a equação 19 acima assume o seguinte aspecto:

$$
\begin{aligned}
& \mathrm{D}_{\mathrm{e}}(\mathrm{A}, \mathrm{B}, \mathrm{C})=\left\{\left[\mathrm{x}_{1}(\mathrm{~A}, \mathrm{~B})-\mathrm{x}_{1}(\mathrm{C})\right]^{2}+\right. \\
& +\left[\mathrm{x}_{2}(\mathrm{~A}, \mathrm{~B})-\mathrm{x}_{2}(\mathrm{C})\right]^{2}+\left[\mathrm{x}_{3}(\mathrm{~A}, \mathrm{~B})-\right. \\
& \left.-\mathrm{x}_{3}(\mathrm{C})\right]^{2}+\left[\mathrm{x}_{4}(\mathrm{~A}, \mathrm{~B})-\mathrm{x}_{4}(\mathrm{C})\right]^{2}+ \\
& +\left[\mathrm{x}_{5}(\mathrm{~A}, \mathrm{~B})-\mathrm{x}_{5}(\mathrm{C})\right]^{2}+\left[\mathrm{x}_{6}(\mathrm{~A}, \mathrm{~B})-\right. \\
& \left.-\mathrm{x}_{6}(\mathrm{C})\right]^{2}+\left[\mathrm{x}_{7}(\mathrm{~A}, \mathrm{~B})-\mathrm{x}_{7}(\mathrm{C})\right]^{2}+ \\
& +\left[\mathrm{x}_{8}(\mathrm{~A}, \mathrm{~B})-\mathrm{x}_{8}(\mathrm{C})\right]^{2}+\left[\mathrm{x}_{9}(\mathrm{~A}, \mathrm{~B})-\right. \\
& \left.-\mathrm{x}_{9}(\mathrm{C})\right]^{2}+\left[\mathrm{x}_{10}(\mathrm{~A}, \mathrm{~B})-\mathrm{x}_{10}(\mathrm{C})\right]^{2}+ \\
& +\left[\mathrm{x}_{11}(\mathrm{~A}, \mathrm{~B})-\mathrm{x}_{11}(\mathrm{C})\right]^{2}+\left[\mathrm{x}_{12}(\mathrm{~A}, \mathrm{~B})-\right. \\
& \left.-\mathrm{x}_{12}(\mathrm{C})\right]^{2}+\left[\mathrm{x}_{13}(\mathrm{~A}, \mathrm{~B})-\mathrm{x}_{13}(\mathrm{C})\right]^{2}+ \\
& +\left[\mathrm{x}_{14}(\mathrm{~A}, \mathrm{~B})-\mathrm{x}_{14}(\mathrm{C})\right]^{2}+\left[\mathrm{x}_{15}(\mathrm{~A}, \mathrm{~B})-\right. \\
& \left.\left.-\mathrm{x}_{15}(\mathrm{C})\right]^{2}+\right\}^{1 / 2}
\end{aligned}
$$

Sendo que:

$D_{e}(\mathrm{~A}, \mathrm{~B}, \mathrm{C})$ - Distância euclidiana entre o perfil competitivo das empresas (A, B) (referências) e da cooperativa, empresa (C) (empresa em estudo).

$X_{1}(\mathrm{~A}, \mathrm{~B})$ - Giro do Ativo das empresas (A, B).

$X_{1}(C)$ - Giro do Ativo da cooperativa, empresa (C).

$X_{2}(\mathrm{~A}, \mathrm{~B})$ - Estruturas de Capitais (DC) das empresas (A, $B)$.

$X_{2}(C)$ - Estruturas de Capitais (DC) da cooperativa, empresa (C).

$X_{3}(\mathrm{~A}, \mathrm{~B})$ - Estruturas de Capitais (WACC) das empresas (A, B).

$X_{3}(C)$ - Estruturas de Capitais (WACC) da cooperativa, empresa (C).

$X_{4}(\mathrm{~A}, \mathrm{~B})$ - EVA Relativo das empresas (A, B).

$X_{4}(C)$ - EVA Relativo da cooperativa, empresa (C).

$X_{5}(A, B)$ - Retorno sobre as Vendas das empresas (A, B).

$X_{5}(C)$ - Retorno sobre as Vendas da cooperativa, empresa (C).

$X_{6}(\mathrm{~A}, \mathrm{~B})$ - Retorno sobre o Ativo das empresas (A, B). 
$X_{6}(\mathrm{C})$ - Retorno sobre o Ativo da cooperativa, empresa (C).

$X_{7}(\mathrm{~A}, \mathrm{~B})$ - Retorno sobre o Patrimônio Líquido das empresas (A, B).

$X_{7}(\mathrm{C})$ - Retorno sobre o Patrimônio Líquido da cooperativa, empresa $(\mathrm{C})$.

$X_{8}(\mathrm{~A}, \mathrm{~B})$ - Índice de Liquidez Corrente das empresas $(\mathrm{A}, \mathrm{B})$.

$X_{8}(\mathrm{C})$ - Índice de Liquidez Corrente da cooperativa, empresa (C).

$X_{9}(\mathrm{~A}, \mathrm{~B})$ - Índice de Liquidez Seca das empresas (A, B).

$X_{9}(\mathrm{C})$ - Índice de Liquidez Seca da cooperativa, empresa $(C)$.

$X_{10}(\mathrm{~A}, \mathrm{~B})$ - Índice de Liquidez Imediata das empresas (A, B).

$X_{10}(\mathrm{C})$ - Índice de Liquidez Imediata da cooperativa, empresa $(C)$.

$X_{11}(\mathrm{~A}, \mathrm{~B})$ - Índice de Liquidez Geral das empresas (A, B).

$X_{11}(\mathrm{C})$ - Índice de Liquidez Geral da cooperativa, empresa $(C)$.

$X_{12}(\mathrm{~A}, \mathrm{~B})$ - Índice de Endividamento Geral das empresas $(\mathrm{A}, \mathrm{B})$.

$X_{12}(\mathrm{C})$ - Índice de Endividamento Geral da cooperativa, empresa (C).

$X_{13}(\mathrm{~A}, \mathrm{~B})$ - Composição do Endividamento de Curto Prazo das empresas (A, B).

$X_{13}(\mathrm{C})$ - Composição do Endividamento de Curto Prazo da cooperativa, empresa (C).

$X_{14}(\mathrm{~A}, \mathrm{~B})$ - Composição de Endividamento de Longo Prazo das empresas (A, B).

$X_{14}(\mathrm{C})$ - Composição de Endividamento de Longo Prazo da cooperativa, empresa $(\mathrm{C})$.

$X_{15}(\mathrm{~A}, \mathrm{~B})$ - Sustentabilidade do Endividamento, das empresas (A, B).

$X_{15}(\mathrm{C})$ - Sustentabilidade do Endividamento, da cooperativa, empresa $(\mathrm{C})$.

Porém, outro procedimento necessitou ser feito: a conversão de posição de grandeza, pois enquanto as variáveis do Giro do Ativo, Geração de Valor Agregado da Ação ou Quota-Parte (EVA) Relativo, as Lucratividades ou Taxas de Retornos e os índices de Liquidez para suas medições foram considerados melhores quanto maiores se apresentaram. As dívidas sobre capitalização (DC), médias ponderadas de capital (WACC), os índices de Endividamento e a Sustentabilidade do Endividamento foram considerados melhores quanto menores foram. Como essas grandezas precisam ser somadas para a determinação da distância euclidiana, sua consideração, na forma em que se apresentaram, pode induzir a resultados de difícil interpretação. Nesse sentido, todas as variáveis (quanto menores, melhores) adotaram uma nova posição de grandezas (quanto maiores, melhores), através da equação 21 :

$$
X=1-V r
$$

Sendo que:

$V r=$ Variável Reposicionável.

Contudo, não basta as variáveis ainda apresentarem grandezas não comparáveis diretamente. O Giro do Ativo e os Índices de Liquidez são números puros; já a Geração de Valor Agregado da Ação ou Quota-Parte (EVA) Relativo, as análises de Estrutura de Capitais (DC-WACC), Lucratividade ou Retornos e Endividamentos são em porcentagem. Como essas grandezas também precisam ser somadas para a determinação da distância euclidiana, sua consideração, na forma em que se apresentam, pode induzir novamente a resultados de difícil interpretação. Para contornar esse problema, Bussab, Miazaki e Andrade (1990) recomendam a utilização de "variáveis padronizadas", que são um recurso bastante usual na estatística. Todas as variáveis foram reduzidas a números puros, eliminando-se, dessa maneira, as diferentes unidades de medida para cada variável estudada, conforme equação 22 :

$$
z_{i}=\frac{x_{i}(.)-\bar{x}_{i}}{s_{i}}
$$

Sendo que:

$\bar{x}_{i}$ e $s_{i}$ indicam, respectivamente, a média e o desvio padrão da i-ésima variável.

Feita a transformação, a distância euclidiana, pelos mesmos autores, passa então a ser expressa pela equação 23:

$$
D_{e}(\mathrm{~A}, \mathrm{~B}, \mathrm{C})=\left\{\sum\left[z_{i}(\mathrm{~A}, \mathrm{~B})-z_{i}(\mathrm{C})\right]^{2}\right\}^{1 / 2}
$$

Como se pode observar, o cálculo da distância euclidiana foi processado de maneira análoga à proposta pela equação 23 , com a diferença que agora as variáveis utilizadas estão em sua forma padronizada.

Comentário equivalente pode ser feito quanto ao cálculo da distância euclidiana entre os perfis competitivos das empresas padrões e o perfil competitivo da cooperativa. A relação pode ser aplicada da mesma 
forma como proposta, desde que se tome o cuidado de utilizar para cada variável o seu valor padronizado.

\section{Apresentação e análise dos resultados}

Após a definição dos métodos que serviram de base para a coleta de dados da pesquisa e submetê-los aos cálculos que geram as categorias de variáveis competitivas econômico-financeiras, passa-se a exibi-los de modo sistemático, de maneira a oferecer informações analíticas. Nesta direção, apresentam-se fatores, elementos e resultados referentes a cada uma das cooperativas em análise.

\subsection{Análise de agrupamento (AA) cluster analysis}

O intento de reunir características similares de cooperativas, através do gráfico de esquema hierárquico, denominado de dendograma (árvore), para se determinar grupos é um estudo importante. A importância reside na possibilidade de se estabelecerem correlações comparativas entre um grupo de duas cooperativas que mais se pareçam competitivamente do ponto de vista econômico-financeiro e, dessas, com a maior distância com outro grupo de cooperativas menos parecidas. Neste caso, utilizou-se o método de complete linkage ou do vizinho mais longe.
Os resultados advindos dessa mensuração, mostrados na Figura 1, correspondem aos dados totais da amostra, num período de análise de quatro anos. A parecença, apresentada inicialmente, está entre as cooperativas Copagril e C. Vale, formando o grupo 1, com distância euclidiana igual a (1). Em seguida, a cooperativa Lar com a Copacol, formando o grupo 2, com distância igual a (8). Posteriormente, o grupo 2 mede distância com a Coopavel, formando o grupo 3, com distância igual (17).

Cumprida a função de comparar e classificar as cooperativas em estudo, o gráfico dendograma permite fazer a afirmativa de que existe uma dissimilaridade significativa entre elas. Este fato chama a atenção, pois significa que as ações de gestão, no que se referem à sustentabilidade econômico-financeira, são díspares. Essa técnica de agrupamento (AA) cumpriu sua função e não torna possível fazer, nesse momento, qualquer inferência sobre qual é a mais competitiva das cooperativas analisadas. Para essa análise, passa-se a utilizar outra técnica a de "coeficiente de parecença", que admite medir a competitividade por meio da distância euclidiana simples.

\subsection{A determinação da distância competitiva e dissimilaridade}

Para ser possível a mensuração de distância competitiva das cooperativas, necessita-se de padrões de referências. Neste estudo, adotou-se a cooperativa

Figura 1. Agrupamento econômico-financeiro das cooperativas

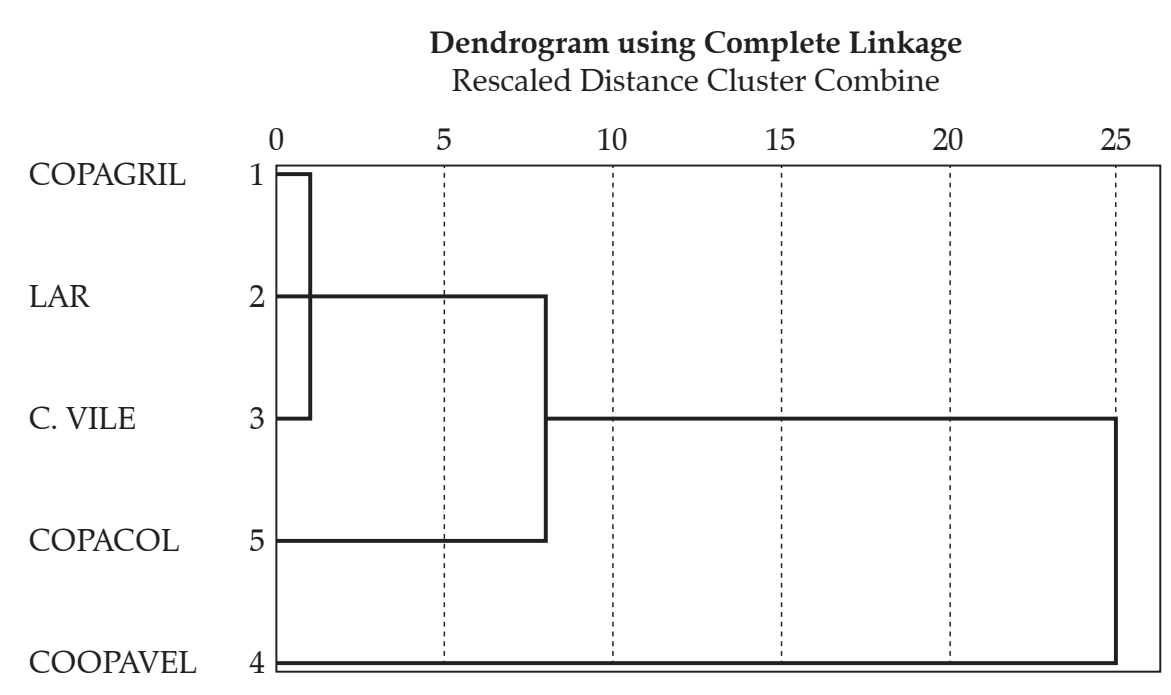

Fonte: Dados da pesquisa (2015). 
Coamo e a empresa BRF. Nesse sentido, estabeleceu-se um coeficiente de parecença que mostrou as dissimilaridades entre o perfil competitivo da cooperativa em estudo que foi analisada, comparativamente aos padrões estabelecidos.

Através da quantificação, a análise será feita com base no valor obtido: quanto maior, mais distante e menos competitiva será a cooperativa, conforme apresentado na Tabela 1.

Com os dados da Tabela 1, permite-se a análise temporal da evolução de competitividade da cooperativa em estudo, por ano, e durante todo o período dos últimos quatro anos.

Pela ordem da Tabela 1, o primeiro caso (a Copagril em relação à Coamo) apresenta uma piora de competitividade de 2011 para 2012, que se recupera em seguida, obtendo melhora em 2013 e 2014; no período, ela alcança de distância $(3,812)$. Quando a mesma toma como referência a empresa BRF, tem piora constante; alcançando distância no período de $(4,437)$.

Por sua vez, a cooperativa Lar, em relação à Coamo, vive uma inconstância: perde competitividade de 2011 para 2012, volta a melhorar em 2013, mas perde novamente em 2014; alcançando distância no período de $(3,376)$. Na sua relação com a empresa BRF, ela vai perdendo competitividade, com exceção de 2013 quando teve leve recuperação em relação ao ano anterior. No período, alcança distância de $(4,026)$.

Quanto à cooperativa C. Vale, esta, vai perdendo competitividade em relação à Coamo, de 2011 a 2013, ganhando em 2014. Alcançou distância igual a (3,099). Quando submetida à referência com à BRF, a $\mathrm{C}$. Vale piora durante todo o período, chegando a uma distância igual a $(4,280)$.

Tomando a Coopavel como análise, ela melhora sua competitividade no período de 2011 a 2012 em rela- ção à Coamo, mas em 2013 e 2014 perde, obtendo distância igual a $(5,294)$. No comparativo com a BRF, ela vai perdendo competitividade ao longo de todo o período, alcançando distância igual a $(5,703)$.

$\mathrm{Na}$ última análise, à Copacol quando referenciada com à Coamo, apresenta pequena perda de competitividade de 2011 para 2012, recuperando-se bem em 2013 e melhor ainda em 2014, com distância nessa relação igual a $(2,306)$. No comparativo com a BRF, vai perdendo competitividade ao longo de todo o período e chega com distância nessa relação igual a $(3,024)$.

Quando se utiliza a visualização gráfica, fica mais fácil e rápido perceber as relações dos dados analisados, a partir da Tabela 1, conforme se apresenta na Figura 2.

Com os resultados apresentados na Figura 2, pode-se afirmar que a cooperativa Copacol tem o melhor perfil de sustentabilidade econômico-financeiro, com a melhor competitividade das cooperativas em estudo com relação aos dois padrões competitivos adotados. Cabe ressaltar, porém, que ela é mais competitiva em relação à Coamo do que à $\mathrm{BRF}$.

Em seguida, apresenta-se a cooperativa C.Vale, em segundo lugar geral; no entanto, na relação com a BRF, ela perde posição para a Lar, ficando em terceiro lugar, mas recupera-se em relação à Coamo.

Em terceiro lugar geral, apresenta-se a cooperativa LAR, mais competitiva do que a C.Vale em relação à $\mathrm{BRF}$, ficando em segundo lugar. Porém, quando submetida à comparação com a Coamo, fica mais dissimilar, assumindo o terceiro lugar.

A Copagril aparece em quarto lugar geral, comparada com as referências Coamo e BRF.

A cooperativa menos competitiva aos dois padrões estabelecidos, dentre as cinco estudadas, é a Coopavel; porém, ela é mais competitiva em relação à Coamo do que no comparativo com a BRF.

Tabela 1. Distância euclidiana econômico-financeira das cooperativas

\begin{tabular}{lcccccccccc}
\hline \multirow{2}{*}{ COOPERATIVAS } & \multicolumn{2}{c}{2011} & \multicolumn{2}{c}{2012} & \multicolumn{2}{c}{2013} & \multicolumn{2}{c}{ 2014 } & \multicolumn{2}{c}{ No Período } \\
\cline { 2 - 11 } & COAMO & BRF & COAMO & BRF & COAMO & BRF & COAMO & BRF & COAMO & BRF \\
\hline COPAGRIL & 1,677 & 1,227 & 1,911 & 1,785 & 1,864 & 2,459 & 1,702 & 2,613 & 3,812 & 4,437 \\
LAR & 1,708 & 1,419 & 1,714 & 1,881 & 1,230 & 1,839 & 1,575 & 2,359 & 3,376 & 4,026 \\
C. VALE & 1,389 & 1,408 & 1,521 & 1,740 & 1,532 & 2,241 & 1,437 & 2,477 & 3,099 & 4,280 \\
COOPAVEL & 2,902 & 2,433 & 2,572 & 2,712 & 2,228 & 2,800 & 2,258 & 3,036 & 5,294 & 5,703 \\
COPACOL & 1,104 & 1,050 & 1,175 & 1,264 & 0,881 & 1,490 & 0,766 & 1,739 & 2,306 & 3,024 \\
\hline
\end{tabular}

Fonte: Dados da pesquisa (2015). 
Figura 2. Dissimilaridade econômico-financeira das cooperativas

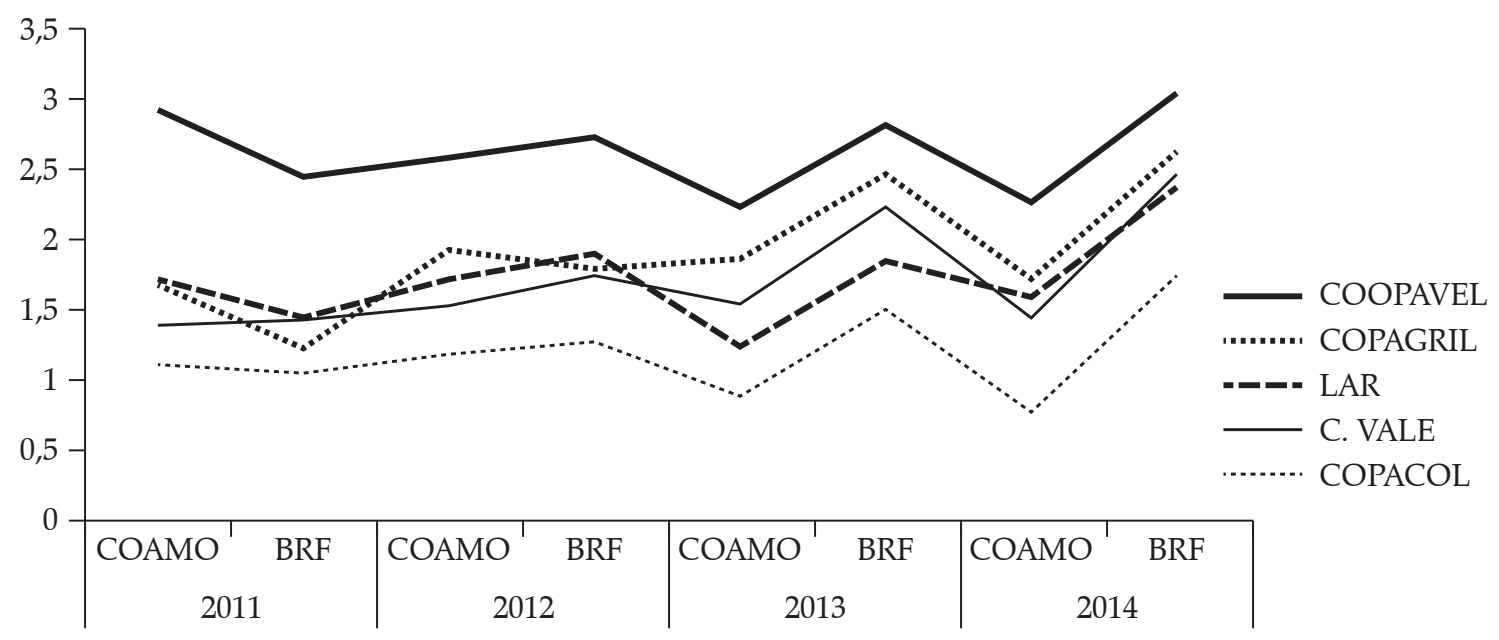

Fonte: Dados da pesquisa (2015).

\section{Conclusões}

Diante das informações, produzidas, a partir dos dados pesquisados, com base no perfil econômico-financeiro, apresenta-se a análise comparativa de competitividade das cooperativas agroindustriais do oeste do Paraná.

A Copacol apresentou-se, dentre as demais cooperativas estudadas, com a melhor sustentabilidade econômico-financeira; portanto, a mais competitiva em relação aos padrões estabelecidos, alcançando a menor distância euclidiana simples, com a cooperativa Coamo e na relação com a empresa BRF.

O que fez da cooperativa Copacol a mais competitiva foi o desenvolvimento de estratégias que geraram capacidade de apresentar eficiência na maioria das variáveis econômicas e financeiras analisadas, como na capacidade de geração de Receitas Líquidas no uso de seu Ativo Total; também destaca-se na relação do uso eficiente de Capital de Terceiros para fazer frente às suas dívidas (DC); uma relação boa entre as médias ponderadas de uso de capitais (WACC); destaque também sobre as Taxas de Retornos sobre Vendas, em que tem o melhor retorno (sobras/lucros) líquido sobre seu faturamento; também nos seus Índices de Liquidez (Corrente, Seca, Imediata e Geral), que medem a capacidade da cooperativa em honrar seus compromissos à medida que eles forem vencendo. E, por fim, no menor índice de Endividamento Geral, que é a sua capaci- dade de geração de sobras (lucros) como o menor uso de capitais de terceiros.

Por sua vez, o que está impedindo que a cooperativa Copacol tenha ainda mais competitividade em relação às demais cooperativas estudadas e a própria BRF, consequentemente, aproxime-se mais da Coamo, foi a destruição do Capital de seus cooperados (EVA) Relativo; no baixo retorno sobre seus Ativos, também chamado de retorno sobre o investimento da empresa, que mede a eficiência global da administração na geração de resultados (sobras/lucros), usando seus ativos disponíveis; baixos retornos sobre o Patrimônio Líquido, que mede o retorno obtido sobre os investimentos dos proprietários na empresa e, por fim, no seu Endividamento de Curto Prazo ou seja, a maior parte de seu endividamento está no curto prazo e não no longo.

A cooperativa C. Vale apresentou-se em segundo lugar geral, mas, quando comparada com a BRF, perdeu a posição para a Lar. No somatório geral conseguiu se recuperar e assume essa posição. Neste caso, o que tem a seu favor na análise econômica é um bom Giro do Ativo; uma boa relação das dívidas com suas capitalizações (DC) e uma boa média ponderada de seus capitais (WACC). Nos aspectos financeiros, uma ótima Liquidez Geral, uma boa Liquidez (Corrente, Seca, Imediata), um bom índice de Endividamento Geral e de Sustentabilidade do Endividamento.

Os aspectos que a tornaram com baixa competitividade foram, principalmente, as Taxas de Retorno, 
tanto em Vendas, como do Ativo e sobre o Patrimônio Líquido. Também possui situação ruim em relação aos prazos de suas dívidas que estão bastante carregadas no curto prazo, gerando relação baixa de dívidas no longo prazo. E, por fim, a C. Vale também se apresenta destruindo o Capital de seus cooperados.

A cooperativa Lar alcançou o terceiro lugar geral e o segundo lugar relativo, comparada com a BRF.

Dentre as variáveis favoráveis à esta posição estão, principalmente, os seus índices de Endividamento, tanto de curto e longo prazos, como também sua Sustentabilidade do Endividamento, que fez dela a mais competitiva das cinco. Também apresentou boa Liquidez (Corrente, Seca, Imediata e Geral) e Taxa de Retorno sobre as Vendas e sobre o Patrimônio Líquido.

O que a fez perder competitividade para a Copacol e para as empresas referências foi a sua situação econômica, ou seja: baixo Giro do Ativo, uma relação ruim das suas dívidas com as capitalizações (DC); uma relação ruim entre as médias ponderadas de uso de capitais (WACC); com índice desfavorável de Endividamento Geral e, principalmente, ela foi a que mais destruiu o Capital de seus cooperados.

A cooperativa Copagril apresentou-se em quarto lugar no comparativo com a Coamo e com a BRF, razão pela qual apresentou favoravelmente boas Taxas de Retornos (Vendas, Ativo e Patrimônio Líquido); boa Liquidez (Corrente, Seca, Imediata e Geral) e boa situação em relação ao seu Giro do Ativo, suas dívidas em relação à capitalização (DC); boa relação em suas médias ponderadas de capitais (WACC).

Os aspectos que a colocaram em quarto lugar dentre as demais e comprometeu sua competitividade com as empresas referências foram os problemas de Endividamento (Geral, de Curto e Longo Prazo), sua Sustentabilidade do Endividamento e, finalmente, também foi destruidora de Capital de seus cooperados.

Com o pior resultado, no comparativo com as outras quatro cooperativas estudadas, apareceu a cooperativa Coopavel que teve a seu favor um bom Giro do Ativo; uma boa Taxa de Retorno sobre o Ativo e sobre o Patrimônio Líquido e na agregação de valor ao Capital de seus cooperados em 2012, 2013 e 2014, alcançando saldo positivo de agregação no período analisado.

O que prejudicou a Coopavel foi uma relação ruim de suas dívidas com a capitalização (DC); uma média ponderada ruim do uso de capitais (WACC); Taxas de Retorno sobre Vendas ruins; todos os índi- ces de Liquidez (Corrente, Seca, Imediata e Geral) muito ruins e também os Endividamentos (Geral, Curto Prazo e Longo Prazo) e sua Sustentabilidade de Endividamento.

Destarte, afirma-se também que existiu uma relação significativa de dissimilaridades de ações entre as cooperativas estudadas, pois quando os dados foram submetidos à análise de agrupamento (dendograma) houve uma distância significativa entre os grupos similares. Distância igual a (24), apresentada entre o grupo 1 (Copagril/C.Vale), ao grupo 4 (Coopavel). Isto pode demonstrar que as ações das cooperativas coirmãs, situadas em regiões similares, geográfica, social, cultural, econômica e politicamente são díspares, ou seja, não praticam ações suficientes de cooperações que venham a fortalecer a competitividade econômico-financeira do sistema cooperativo agroindustrial exportador em estudo.

E, finalmente, afirma-se que houve a assertiva dos autores da pesquisa quando determinaram aleatoriamente como padrões de referências a cooperativa Coamo e a empresa BRF, pois nenhuma cooperativa estudada igualou-se (distância euclidiana simples igual a zero) aos padrões estabelecidos. O fato de a cooperativa mais competitiva neste perfil apresentado ser a Copacol, e esta apresentar distância euclidiana simples significativa no período de quatro anos, de $(2,306) \mathrm{com}$ a cooperativa Coamo, e de $(3,024)$ com a empresa BRF, revelou baixa competitividade econômico-financeira das cooperativas estudadas no oeste do Paraná.

Sugere-se que novas pesquisas sejam realizadas com as cooperativas agroindustriais, abordando a competitividade a partir de variáveis internas envolvendo as estruturas de mercado, produção e o uso de tecnologia, procurando identificar similaridades nos usos, por exemplo: de tecnologia, intensidade de capital, inovação de processos ou na participação de mercados, eficiência em vendas, crescimento das exportações e outros.

\section{Referências}

ASSAF NETO, A. e LIMA, F. G. Administração financeira. 2. ed. São Paulo: Atlas, 2011.

BIALOSKORSKI NETO, S. Governança e perspectivas do cooperativismo. Revista Preços Agrícolas - ESALQ, Piracicaba, abr. 1999, p. 1-22. 
Economia e gestão de organizações cooperativas.

São Paulo: Atlas, 2012.

BRASIL. Lei $n^{\circ}$. 5.764, de 16 de dezembro de 1971. Define a política nacional de cooperativismo, institui o regime jurídico das sociedades cooperativas, e dá outras providências. Disponível em: < http://www.planalto. gov.br>. Acesso em: 20 jun. 2014.

BRF BRASIL FOODS. Disponível em: < http://www. brf.com.br>. Acesso em: 20 mar. 2015.

BRIGHAM, E. F. e HOUSTON, J. F. Fundamentos da moderna administração financeira. Trad. de Maria Ilmida da Costa e Silva. Rio de Janeiro: Campus, 1999.

BUSSAB, W. O., MIAZAKI, S. E. e ANDRADE, D. F. Introdução à análise de agrupamento. In: SIMPÓSIO BRASILEIRO DE PROBABILIDADE E ESTATÍSTICA, 9, 1990, São Paulo. Anais... São Paulo: USP, 1990.

C.VALE - Cooperativa Agroindustrial Palotina - Pr. Disponível em: < http://www.brf.com.br > Acesso em: 20 mar. 2015.

CHURCHILL, G. A. e PETER, J. P. Marketing: criando valor para os clientes. Trad. Célia Camargo Bartalotti e Cid Knipel Moreira. São Paulo: Saraiva, 2003.

COOPAVEL - Cooperativa Agroindustrial Cascavel Pr. Disponível em: <http://www.brf.com.br>. Acesso em: 20 mar. 2015.

COPACOL - Cooperativa Agroindustrial Consolata Cafelândia - Pr. Disponível em: < http://www.copacol. com.br $>$. Acesso em: 20 mar. 2015.

COPAGRIL - Cooperativa Agroindustrial Marechal Cândido Rondon - Pr. Disponível em: < http://www. brf.com.br>. Acesso em: 20 mar. 2015.

DOSI, G. eFREEMAN,C. The diversity of devepeloment patterns: on the process of the catching-up, forging ahead, and falling behind. In: INTERNATIONAL ECONOMIC ASSOCIATION CONGRESS. Paper. Varena: 1992.

FARINA, E. M. M. Q., AZEVEDO, P. F. e SAES, M. S. M. Competitividade: mercado, estado e organizações. São Paulo: Singular, 1997.

FREI, F. Introdução à análise de agrupamento. São Paulo: UNESP, 2006.

GREENWALD, B. C. N. e KAHN, J. A estratégia competitiva desmistificada. Trad. Ricardo Bastos Vieira. Rio de Janeiro: Elsevier, 2006.

HAIR JR., J. F. et al. Análise multivariada de dados. 6. ed. Porto Alegre: Bookman, 2009.
ILHA, P. C. O Crescimento e o desenvolvimento de cooperativas agropecuárias do Oeste do Paraná. 2010. $151 \mathrm{f}$. Dissertação (Mestrado em Desenvolvimento Regional e Agronegócio) - Universidade Estadual do Oeste do Paraná, Toledo, 2010.

ILHA, P. C. S. et al. Uma Análise Comparativa da Competitividade das Cooperativas Agroindustriais do Oeste do Paraná, sob as Perspectivas EconômicoFinanceiras, Tecnologias de Produção e dos Mercados. In: 54º Congresso da SOBER - Sociedade Brasileira de Economia, Administração e Sociologia Rural, 2016, Maceió - AL. 54ํㅡㄹ Congresso da SOBER, 2016.

KOTLER, P. e ARMSTRONG, G. Princípios de marketing. São Paulo: Prentice Hall do Brasil, 2008.

LAR. Cooperativa Agroindustrial Medianeira - Pr. Disponível em: < http://www.brf.com.br>. Acesso em: 20 mar. 2015.

MARION, J. C. Contabilidade empresarial. 16. ed. São Paulo: Atlas, 2012.

MATARAZZO, D. C. Análise financeira de balanços: abordagem básica e gerencial. 7. ed. São Paulo: Atlas, 2010.

PORTER, M. E. Vantagem competitiva: criando e sustentando um desempenho superior. Trad. Elizabeth Maria de Pinho Braga. Rio de Janeiro: Elsevier, 1989.

\section{1.} . Estratégia competitiva. Rio de Janeiro: Campus,

PRESNO, N. As cooperativas e os desafios da competitividade. Revista de Estudos Sociedade e Agricultura, v. 17, p. 119-144, out. 2001.

RANKBRASIL. Recordes brasileiros. Disponível em: <http://www.rankbrasil.com.br>. Acesso em: 18 nov. 2014.

SCHUMPETER, J. A. Teoria do desenvolvimento econômico. São Paulo: Abril Cultura, 1982. (Série “Os economistas").

SILVA, J. P. Análise financeira das empresas. 11. ed. São Paulo: Atlas, 2012.

SOUZA, U. R. D., BRAGA, M. J. e FERREIRA, M. A. $\mathrm{M}$. Fatores associados à eficiência técnica e de escala das cooperativas agropecuárias paranaenses. Revista de Economia e Sociologia Rural, v. 49, n. 3, p. 573-597, 2011.

YIN, R. K. Estudo de caso: planejamento e métodos. 4. ed. Porto Alegre: Bookman, 2010.

ZYLBERSZTAJN, D. Análise comparativa de sistemas agroindustriais. São Paulo: USP/PENSA, 1995. 18 p. (Série Estudos Temáticos PENSA/USP).

Todo o conteúdo deste periódico, exceto onde estiver identificado, está licenciado sob uma Licença Creative Commons (cc by 4.0) 
